\title{
CLINICAL EXPERIENCE IN THE MANAGEMENT OF PEDIATRIC WILMS TUMOR
}

\author{
Haithem Hussein Ali Almoamin*, Ansam Mahmood Saleh ${ }^{\circledR}$, Athar \\ Abdulsamad Majeed\$, \& Hussam Mahmood Saleh".
}

*MB,ChB, FIBMS (Pediatric Surg.), Assistant Professor Al-Zahraa College of Medicine, University of Basrah, Consultant Pediatric Surgeon, Basrah Children Specialty Hospital. @\$\# MB,ChB, FIBMS (Pediatrics), Basrah Children Specialty Hospital, Basrah, IRAQ.

\begin{abstract}
Wilms tumor is the commonest renal tumor in children. This study aimed to evaluate the characteristics, diagnosis, treatment, and outcome of Wilms tumor in pediatric age group and to analyze factors affecting the outcome.

This retrospective study included 61 children younger than 15 years with Wilms tumor who were managed at Basrah Children Specialty Hospital during the period between 2011 and 2016. Patients' characteristics, mode of diagnosis, treatment modalities, complications, relapse, and outcome were all reviewed.

The results showed that Wilms tumor was the commonest tumor affecting the kidneys (85\%). The median age of onset was 30 months, and mostly in children aged 2-4 years. The most common presenting feature was abdominal mass $(44.3 \%)$. Twenty three patients were diagnosed as stage $1(37.7 \%)$. Favorable histology Wilms tumor was encountered in only $65.6 \%$. Tumor relapse was seen in 12 patients $(19.7 \%)$, eight of them died $(66.7 \%)$. The overall 2-year survival was $70.5 \%$ (43 cases).

In conclusion, Wilms tumor is the most common renal tumor with high rate of unfavorable histology (anaplasia) in our society. Stage I tumor is the predominant stage but unfortunately carries a relatively high mortality. Advanced stages still represent a significant proportion which may reflect poor awareness and delayed diagnosis which thereafter worsens the outcome. Advanced stages, presence of anaplasia, and tumor relapse are the major factors affecting survival of children with Wilms tumor.

Keywords: Renal tumors, Wilms, Staging, Histology, Outcome
\end{abstract}

\section{Introduction}

Renal tumors are the 2nd most common abdominal tumors in pediatric age group next to neuroblastoma ${ }^{1}$. Wilms tumor is the commonest malignant tumor that affects the kidneys in children ${ }^{2}$ as it accounts for $6 \%$ of cancers in pediatric age group. About $95 \%$ of renal tumors in the pediatric age group are diagnosed as Wilms tumor ${ }^{3}$. The mean age at diagnosis is 3 years with most children presenting between the ages of one and four ${ }^{4}$. The sex ratio is approximately $1: 1^{5}$. Most patients with Wilms tumor present with a painless abdominal mass ${ }^{6}$. The preferred radiological method for evaluating children with suspected Wilms tumor is CT $\operatorname{scan}^{7}$. Multidisciplinary therapy has substantially improved survival for Wilms tumor ${ }^{8}$. The treatment for Wilms tumor includes surgery, chemotherapy and sometime radiotherapy ${ }^{1,2,8}$ and the survival rate was $30 \%$ in 1930 compared with more than $90 \%$ today ${ }^{4,8,9}$.

\section{Patients and methods}

This is a single institution retrospective review of children younger than 15 years with renal tumors who were managed at Basrah Children Specialty Hospital in Iraq during the period between 2011 and 2016. A total of 72 patients were studied, of them 61 patients were diagnosed as Wilms tumor. Those patients with Wilms tumor were evaluated regarding age, 
gender, side affected, presenting features, histology favorability, staging, diagnostic modality, treatment combinations, complications, relapse, and survival.

Diagnosis was confirmed by histopathological examination of resected tumor for operable tumors or tumor biopsy for non-operable tumors. Staging, grading, and treatment modalities followed the system of National Wilms Tumor Study Group-5 (NWTSG-5).

Treatment comprised of a radical nephrectomy for unilateral operable tumor, followed by chemotherapy and, in some cases, radiotherapy. Secondary deposits (15 cases), caval invasion (one case), or those with bilateral tumors (2 cases) received chemotherapy and delayed radical nephrectomy. Chemotherapy included DD-4A $\mathrm{x}$ 18 week for stage I and II Fav
(Vincristine+Dactinomycin), DD-4A $\mathrm{x}$ 24week for III-IV Fav (Vincristine, Dactinomycin, doxorubicin), or five drugs (Vincristine, Dactinomycin, doxorubicin, Cyclophosphamide, Etoposide) for Wilms tumor with anaplastic features and for other high-risk renal Tumors ${ }^{10}$. Radiation was given to stage III and IV disease, rupture during surgery, gross residual disease, or lung metastasis at initial diagnosis. Data were analyzed using SPSS v. 20.

\section{Results}

This study included 72 children presented with renal tumors. Wilms tumor was the commonest tumor affecting the kidneys in pediatric age group (85\%). The types of pediatric renal tumors in our study are demonstrated in fig.1.

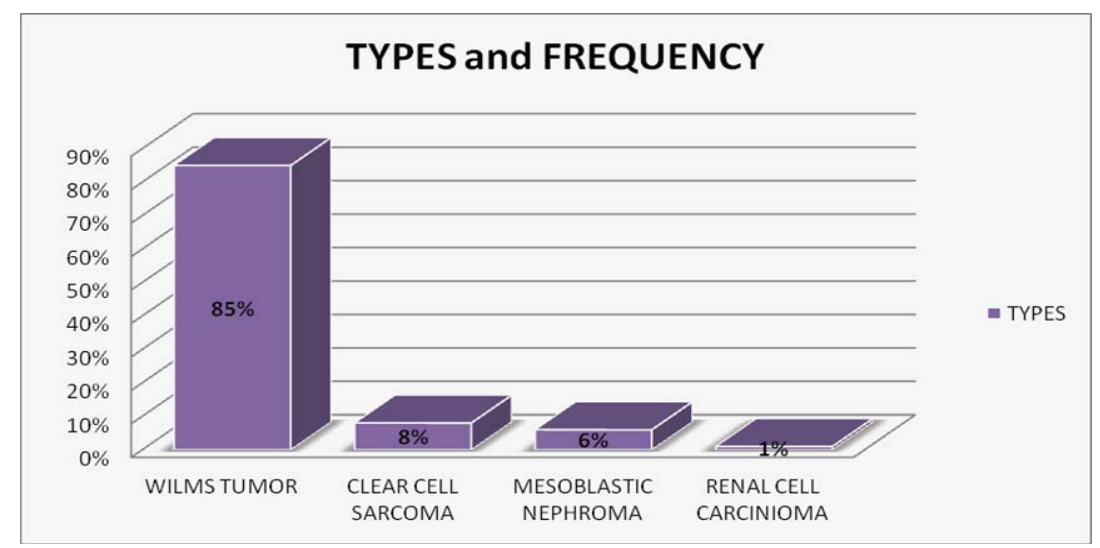

Figure 1: The types of pediatric renal tumors

This study showed that the commonest age affected by Wilms tumor was 2-3 year (29.5\%), followed by $3-4$ years $(19.7 \%)$, and in infancy it was $14.6 \%$ as shown in fig. 2 .

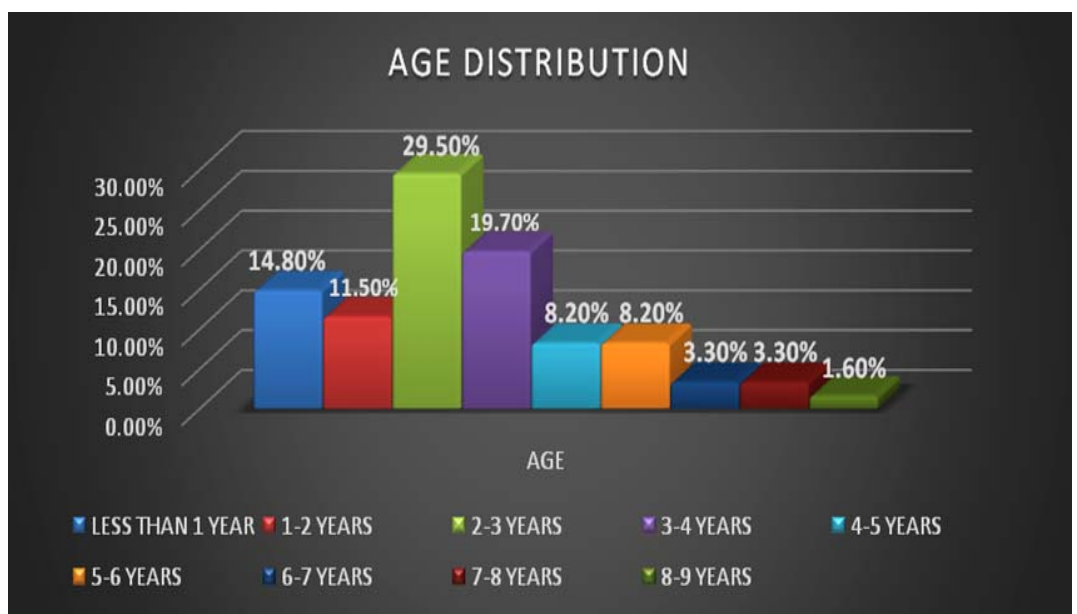

Figure 2: Age distribution of pediatric Wilms tumor. 
Males (27 cases) were slightly less affected than females (34 cases) with a ratio of (0.8:1). Left kidney (36 cases) was affected more than the right one (23 cases) $59 \%$ vs $37.7 \%$ respectively. Bilateral tumor was detected in only two patients $(3.3 \%)$.

The most common presenting feature was abdominal mass (44.3\%). Asymptomatic tumor discovered accidentally was the second common $(19.7 \%)$, followed by hematuria (11.5\%). Fever/night sweat was found in $8.2 \%$, while hypertension or abdominal pain was found in four cases each $(6.6 \%)$. Frequent vomiting occurred in two cases $(3.3 \%)$. Other presenting features were; frequency, dysuria, weight loss or just irritability in $1.6 \%$ each.

Figure 3; shows different stages of Wilms tumor and that twenty-three patients were diagnosed as stage I (37.7\%). Staging follows NWTSG-5 and confirmed clinically, radiologically, and operatively.

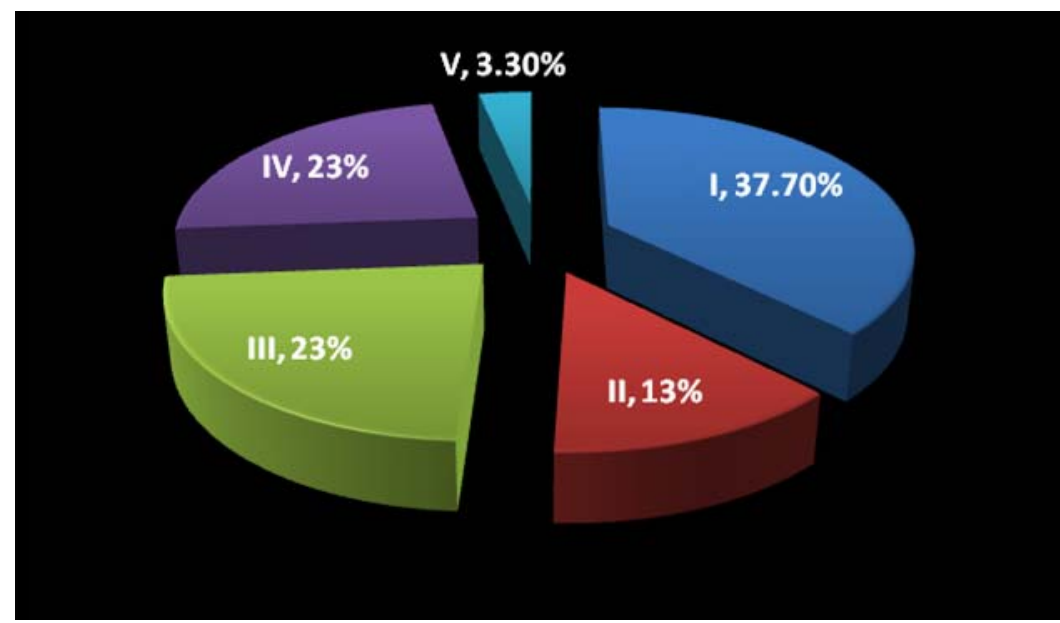

Figure 3: Staging of Pediatric Wilms Tumor

Regarding favorable histology, Wilms tumor was encountered in 40 cases $(65.6 \%)$, while unfavorable histology tumor was detected in 21 cases $(34.4 \%)$ as shown in fig. 4.

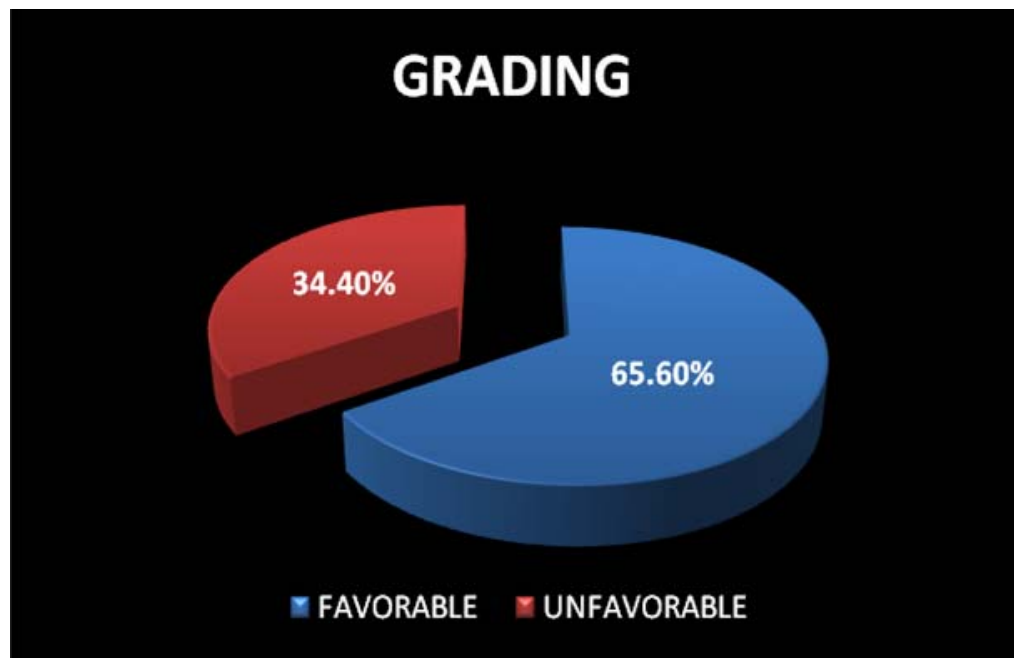

Figure 4: Histopathological grading of pediatric Wilms tumor.

Forty-four patients $(72.1 \%)$ did not have any significant complications. In 12 patients $(19.7 \%)$, the tumor relapsed mostly within one year following completion of treatment. Three patients (4.9\%) developed adhesive intestinal obstruction. Simple wound infection, respiratory failure, and renal failure 
occurred in 2 patients each (3.3\%). Controlled hemorrhage, pleural effusion, and accidental vascular injury to the other kidney occurred in one patient each $(1.6 \%)$.

Tumor relapse was seen in 12 patients (19.7\%), eight of them died (66.7\%). Advanced stages were associated with high relapse rate: stage IV vs. stage I $(42.9 \%$ vs. $4.4 \%)$ In addition, unfavorable histology tumor was associated with higher relapse $(42.9 \%$ vs $7.5 \%)$.

The overall 2-year survival was $70.5 \%$ (43 cases). The highest mortality was seen in stage IV $(64.3 \%)$, while the least mortality was seen in stage II (12.5\%). The treatment type and the outcome in relation to staging are demonstrated in table I.

Table I: Treatment and Outcome of Wilms Tumor in Relation to Staging

\begin{tabular}{|c|c|c|c|c|}
\hline STAGES & No. $(\%)$ & RELAPSE & SURVIVAL & TREATMENT \\
\hline I & $23(37.7 \%)$ & $1(4.4 \%)$ & $82.6 \%$ & Surgery + chemotherapy \\
\hline II & $8(13 \%)$ & $1(12.5 \%)$ & $87.5 \%$ & $\begin{array}{l}\text { Surgery }+ \text { chemotherapy }+/- \\
\text { radiotherapy }\end{array}$ \\
\hline III & $14(23 \%)$ & $4(28.6 \%)$ & $78.6 \%$ & $\begin{array}{l}\text { Chemotherapy }+ \text { surgery }+ \\
\text { radiotherapy }\end{array}$ \\
\hline IV & $14(23 \%)$ & $6(42.9 \%)$ & $35.7 \%$ & $\begin{array}{l}\text { Chemotherapy }+ \text { surgery }+ \\
\text { radiotherapy }\end{array}$ \\
\hline $\mathrm{V}$ & $2(3.3 \%)$ & $0 \%$ & $50 \%$ & Chemotherapy + surgery \\
\hline TOTAL & $61(100 \%)$ & $12(19.7 \%)$ & $43(70.5 \%)$ & \\
\hline
\end{tabular}

Mortality rate of favorable histology tumor was $7.5 \%$, while of unfavorable histology tumor was $71.4 \%$. The outcome of Wilms tumor in relation to histopathological Grading is shown in Table II.

Table II: Outcome of Wilms Tumor in Relation to Grading

\begin{tabular}{l|l|l|l}
$\begin{array}{l}\text { GRADING } \\
(\text { HISTOPATHOLOGY) }\end{array}$ & NO. $(\%)$ & $\begin{array}{l}\text { RELAPSE } \\
\text { NO. }(\%)\end{array}$ & $\begin{array}{l}\text { SURVIVAL } \\
\text { NO. }(\%)\end{array}$ \\
\hline FAVORABLE & $40(65.6 \%)$ & $3(7.5 \%)$ & $37(92.5 \%)$ \\
\hline UNFAVORABLE & $21(34.4 \%)$ & $9(42.9 \%)$ & $6(28.6 \%)$ \\
\hline TOTAL & 61 & $12(19.7 \%)$ & $43(70.5 \%)$
\end{tabular}

Significant association was documented for staging, grading, tumor relapse, metastasis, and complications and the mortality Wilms risks were shown in table III.

Table III: Mortality Risk Factors for pediatric Wilms tumor.

\begin{tabular}{l|l|l} 
ITEM & Chi square & P-value \\
\hline STAGING & 11.719 & 0.020 \\
\hline GRADING & 27.056 & 0.000 \\
\hline METASTASIS & 9.882 & 0.020 \\
\hline COMPLICATIONS & 20.519 & 0.009 \\
\hline RELAPSE & 8.788 & 0.003
\end{tabular}




\section{Discussion}

Basrah Children Specialty Hospital is a tertiary hospital in the south of Iraq. Children with surgical diseases or cancer are referred to our hospital that has a multidisciplinary team of cancer specialists.

As recorded by other researches, Wilms tumor is the commonest tumor affecting the kidneys in pediatric age group (85\% of all pediatric renal tumors) ${ }^{1,4}$. Clear cell sarcoma of the kidneys represents $8 \%$ of pediatric renal tumors that is higher than reported $1.6 \%{ }^{9}$. Mesoblastic nephroma have affected four patients $(6 \%)$, three of them were atypical. Renal cell carcinoma has affected only one female patient aged 15 years old $(1 \%)$.

The peak incidence was between 2 and 4 years old $(49.2 \%)$ with most tumors affecting children younger than 5 years old $(85 \%)$, and this result agrees with other studies ${ }^{2,11,12}$. The median age at presentation (30 months) was less than reported by NWTSG series (38 months) or other studies, ${ }^{7,13-15}$. The youngest patient was one month old and the oldest patient was 8 and a half years.

This study showed that Wilms tumor was slightly predominant in females $(55.7 \%)$. This result is similar to data from nearby Jordanian and Saudi Arabia results, and in USA ${ }^{13,14,16}$.

Wilms tumor has affected the left kidney in a higher proportion than that of the right one (59\% vs 38\%). In similar study done in Pakistan, right kidney was predominately affected ${ }^{17}$. The incidence of bilateral tumor $(3.3 \%)$ was slightly lower than that seen by others ${ }^{1,11,12}$.

Regarding blood group, $\mathrm{O}+\mathrm{ve}$ was the commonest group affected by Wilms tumor $(36 \%)$, followed by $\mathrm{B}+\mathrm{ve}(30 \%)$, and $\mathrm{A}+\mathrm{ve}(23 \%)$. Rh typing was +ve in the majority of patients with Wilms tumor $(95 \%)$.

In this study, most children presented with abdominal mass (44.3\%) and this result is comparable with other studies $^{4,18,19}$. Asymptomatic accidentally discovered mass was the second common presentation (19.7\%). Many studies concluded higher percentage of asymptomatic tumors discovered accidentally by routine physical examination or by family ${ }^{2,11}$; however, the availability of modern imaging technique may play a role in changing the mode of presentation ${ }^{7}$. Hypertension was found in $6.6 \%$ only and this is lower than seen by others ${ }^{1,2}$. Many nonspecific features e.g. fever, night sweat, abdominal or loin pain, frequent vomiting, frequency of urine, dysuria, weight loss, or just irritability was the first presenting features for Wilms tumor that demand high index of suspicion to early diagnose and thereby to improve survival and prognosis.

This study also analyzed the stages of Wilms tumor in pediatric age group. Stage I disease was fortunately the predominant and accounting for $(37.7 \%)$. Unfortunately, stage II made up only $13.1 \%$ of pediatric Wilms tumor. This result agrees with NWTSG, and SIOP where stage I predominates $(47 \%, 61 \%$ respectively) ${ }^{20,21}$, although, it is different from other study where stage II predominates ${ }^{13}$. Less advanced stages (I and II) accounted for about half of cases of Wilms tumor i.e. there is still a delay in the diagnosis and management that worsen prognosis. In a study performed in Pakistan, advanced staged disease accounted for $74 \%$ of Wilms tumor and similar result recorded in South Africa $^{17,22}$, but in nearby countries, less advanced stages were also reported by a Jordanian, Saudi and Egyptian studies ${ }^{13,14,23}$.

A major factor predictive of aggressiveness is histological finding of anaplasia, whether focal or diffuse $e^{1,4,24}$. Favorable histology showed Wilms tumor accounted for $65.6 \%$ of patients. Favorability is much lower than seen by other studies ${ }^{1,13,25}$. On the other hand, other studies conducted in Iran and China 
also showed high rate of unfavorable histology Wilms tumor 43.6\%, 31.3\% respectively ${ }^{26,27}$, this fact may reflect the geographical variations of Wilms tumor behavior.

Tumor relapse was seen in 12 patients $(19.7 \%)$ of patients. It is highest in stage IV $(42.9 \%)$ and with unfavorable histology $(42.9 \%)$. This result is similar to other studies ${ }^{9,14,28}$ but still higher than reported by more advanced centers wherein relapse rate was $10 \%{ }^{9}$. Mortality in relapse tumor was high $(66.7 \%)$.

The overall 2-year survival was $70.5 \%$. This is lower than reported by others $^{1,2,4,13,14}$. The best survival was detected in stage II patients (87.5\%), while worst survival was in stage IV (35.7\%). Unfortunately, high mortality was detected in stage I tumor (17.4\%). This unexpected result was studied in details to find out the cause behind this high mortality. Inaccurate staging (although confirmed operatively and histopathologically), failure to sample lymph nodes in many patients, mobilization of tumor before renal pedicle ligation, or unnoticed tumor thrombus migration during resection may be the cause. High percentage of unfavorable histology tumors was encountered in our series and may be the cause behind this high mortality rate.

The 2-year survival rate was $92.5 \%$ ( 37 out of 40) for favorable histology and $28.6 \%$ (6 out of 21 ) for anaplastic tumor.
This data agrees with other studies ${ }^{2,4,13}$. Factors that significantly associated with mortality were staging, grading, tumor relapse, metastasis, and complications. For unclear reason, female patients with Wilms tumor died more frequently than male patients in our study (15 out of 19 females died vs 3 out of 27 males died), (Chi square 7.882, P-value 0.005).

Two patients were diagnosed with bilateral Wilms tumor. One of them died during chemotherapy due to renal failure, the other survived following chemotherapy alone with complete disappearance of tumor and he is doing well on regular follow-up.

Regarding renal tumors, the mortality rate of Wilms tumor was $29.5 \%$ (18 out of 61), while that of clear cell sarcoma of kidneys was $50 \%$ (3 out of 6 ). One patient, who had renal cell carcinoma, died. All four patients who have had mesoblastic nephroma survived.

Conclusion: Wilms tumor is the commonest renal tumor in our society with high rate of unfavorable histology (anaplasia). Stage I tumor is the predominant stage but unfortunately carries a relatively high mortality. Advanced stages still represent a significant proportion which may reflect poor awareness, delayed diagnosis and therefore worsen outcome. Advanced stages, presence of anaplasia, and tumor relapse are the major factors affecting outcome.

\section{References}

1. Peter F. Ehrlich, Robert C. Shamberger, Renal Tumors. In: George W. Holcomb III, Patric J. Murphy, Daniel J. Ostlie, Ashcraft's Pediatric Surgery $6^{\text {th }}$ ed. (2014); 65: 859, 860, 864, 865, 867.

2. Peter M. Anderson, Chetan Anil Dhamne, and Vicki Huff, Neoplasms of the Kidney. In: Robert M. Kliegman, MD, Bonita F. Stanton, MD, Joseph W. St. Geme III, MD, Nina F. Schor, MD, PhD, Richard E. Behrman, MD, Nelson Textbook of PEDIATRICS; 19 ${ }^{\text {th }}$ ed. (2011); 497: 1757, 1758.

3. Andrew M. Davidoff, Nephroblastoma; Moritz M. Ziegler, Richard G. Azizkhan, Daniel von Allmen, Thomas R. Weber. In: Operative pediatric surgery $2^{\text {nd }}$ ed. (2014); 88: 1177.

4. F. Ehrlich, Wilms tumor. In: Peter Mattei, MD, FAAP, FACS, Fundamentals of Pediatric Surgery (2010); 92: 715, 716, and 717 .

5. Norman Breslow, J. Bruce Beckwith, Marcia Gol, and Katrina Sharpies. Age distribution of Wilms' tumor: report from the National Wilms’ Tumor Study. Cancer Res 1988; 48: 1653-1657. 
6. Chrystele Madre, Daniel Orbach, Veronique Baudouin, Herve Brisse, Farida Bessa, Gudrun Schleiermacher, Helene Pacquement, Francois Doz, Jean Michon (2006) Hypertension in childhood cancer: a frequent complication of certain tumor sites. J Pediatr Hematol Oncol 28: 659-664.

7. Edward PTagge, Patrick B. Thomas, and H. Biemann Othersen, Wilms' Tumor. In: Jr. Jay L. Grosfeld, James A. O’Neill Jr, Arnold G. Coran, Eric W. Fonkalsrud, Anthony A. Caldamone, Pediatric surgery. $6^{\text {th }}$ ed. (2006). 27: 446, 448 .

8. Metzger ML and Dome JS (2005) Current therapy for Wilms' tumor. Oncologist 10: 815-826.

9. M F Tournade, C Com-Nougué, J de Kraker, R Ludwig, A Rey, J M Burgers, B Sandstedt, J Godzinski, M Carli, R Potter, J M Zucker, (2001) optimal duration of preoperative therapy in unilateral and nonmetastatic Wilms' tumor in children older than 6 months: results of the Ninth International Society of Pediatric Oncology Wilms' Tumor Trial and Study. J Clin Oncol 19: 488-500).

10. Jeffrey S Dome 1, Cecilia A Cotton, Elizabeth J Perlman, Norman E Breslow, John A Kalapurakal, Michael L Ritchey, Paul E Grundy, Marcio Malogolowkin, J Bruce Beckwith, Robert C Shamberger, Gerald M Haase, Max J Coppes, Peter Coccia, Morris Kletzel, Robert M Weetman, Milton Donaldson, Roger M Macklis, Daniel M Green: Treatment of anaplastic histology Wilms tumor: results from the fifth National Wilms Tumor Study. J Clin Oncol 24 (15): 2352-8, 2006.

11. By Michael W. Mulholland, Keith D. Lillemoe, Gerard M. Doherty, Ronald V. Maier, Diane M. Simeone, Gilbert R. Upchurch. In: Greenfield's surgery: scientific principles and practice; $5^{\text {th }}$ ed. (2011): Ch. 109, 1963, 1964.

12. Pedro-Jose Lopez and Peter Cuckow, Wilms tumor. In: Lewis Spitz MBChB PhD MD(Hon) FRCS (Edin, Eng) FRCSI(Hon) FAAP(Hon) FCS(SA) (Hon) FACS (Hon), Arnold G Coran MD; Operative pediatric surgery. $7^{\text {th }}$ ed. (2013) Ch. 74: 701

13. Maher K. Mustafa M, Mufeed K. Hamoury M, Salma S. Hassan R. (2014); Wilms' Tumor in Children: A Single Institution 10-Year Experience; The Egyptian Journal of Hospital Medicine (April 2014) Vol. 55, Page 159-164.

14. Al Mulhim I (1997): Wilms Tumor in Children: A 10-year Experience from the Eastern Province of Saudi Arabia Saudi J Kidney Dis Transpl., 8(2):123-6.

15. Norman Breslow, J. Bruce Beckwith, Marcia Gol, and Katrina Sharpies. Age distribution of Wilms' tumor: report from the National Wilms' Tumor Study. Cancer Res 1988; 48: 1653-1657.

16. Green DM (1997): Wilms tumor. Eur J Cancer., 33:409-18.

17. Zehra Fadoo, Samia Hussain, Sukaina Panju, Saima Alvi, Kidney tumors in children: A single centre experience from a developing country; Turkish Journal of Cancer 133 Volume 39, No. 4, 2009.

18. Ekenze SO, Agugua-Obianyo NE, O A Odetunde. The challenge of nephroblastoma in a developing country. Ann Oncol 2006; 17:1598-600.

19. Dafalla O. Abuidris MD Mohammed E. Elimam MD Faisal M. Nugud MD Elgaili M. Elgaili MD Mohamed E. Ahmed MD Ramandeep S. Arora. Wilms tumor in Sudan. Pediatr Blood Cancer 2008; 50(6):1135-7.

20. Green DM (2004): The treatment of stages I-IV favorable histology Wilms' tumor. J Clin Oncol., 22: 1366-72.

21. Harald Reinhard, Schahin Aliani, Christian Ruebe, Michael Stöckle, Ivo Leuschner, Norbert Graf (2004): Wilms' tumor in adults: Results of the Society of Pediatric Oncology (SIOP) 93-01/Society for Pediatric Oncology and Hematology (GPOH) Study. J Clin Oncol., 22: 4500-6.

22. Alan Davidson, Patricia Hartley, Farieda Desai, John Daubenton, Heinz Rode, Alastair Millar. Wilms tumor experience in a South African centre. Pediatr Blood Cancer 2006; 46(4):465-71.

23. Abd El-Aal H, Habib EE, Mishrif MM (2005): Wilms' Tumor: The Experience of the Pediatric Unit of Kasr El-Aini Center of Radiation Oncology and Nuclear Medicine (NEMROCK). J Egypt Natl Cancer Inst., 17 (4): 308-14.

24. Kim S, Chung D. Pediatric solid malignancies: neuroblastoma and Wilms' tumor. Surg Clin North Am 2006; 86: 469-487, xi.

25. Michael L Pianezza, Steven Rubin, Juan Bass, Shirley Chou, John G Pike, Michael P Leonard (2004): Wilms' tumor at the Children's Hospital of Eastern Ontario: 1990-2001. Can J Urol., 11(1):2151-6.

26. Mir-Mahmood Seyed-Ahadi, Ahmad Khaleghnejad-Tabari, Alireza Mirshemirani, Naser Sadeghian, Omid Amonollahi (2007): Wilms' Tumor: A 10 Year Retrospective Study. Arch Iranian Med., 10 (1): 65-69.

27. Wei Yao 1, Kai Li, Xianmin Xiao, Jiechun Gao, Kuiran Dong, Xianmin Xiao, Zhibao Lv (2012): Outcomes of Wilms' tumor in eastern China: 10 years of experience at a single center. Surgery-, 25 (3): $181-5$

28. Sherif F. Naguib, M.D.; Alaa EL Haddad, M.D.; Samy A. EL Badawy, M.D. and Ashraf S. Zaghloul, M.D. (2008): Multidisciplinary approach to Wilms' tumor: a retrospective analytical study of 53 patients. J Egypt Natl Canc Inst., 20 (4): 410-23. 